\title{
PREVALENCE OF HYPERTENSION AND ASSOCIATED RISK FACTORS AMONG PATIENTS ATTENDING OUTPATIENT DEPARTMENT OF A TEACHING HOSPITAL IN CENTRAL KERALA
}

\author{
Aravindakshan V. N1, Sholy K. Vareed ${ }^{2}$, Gopalakrishnan Padmanabhan ${ }^{3}$, Swati Patki ${ }^{4}$, Harsha Chollankil Hariharan 5 , \\ Ann Mary Thomas6, Reshma7, Raju Antony ${ }^{8}$

\begin{abstract}
${ }^{1}$ Assistant Professor, Department of General Surgery, Sree Narayana Institute of Medical Sciences, Ernakulam, Kerala. ${ }^{2}$ Assistant Professor, Department of Radio-diagnosis, Sree Narayana Institute of Medical Sciences, Ernakulam, Kerala. ${ }^{3}$ Associate Professor cum Epidemiologist, Dept. of Community Medicine, Sree Narayana Institute of Medical Sciences, Ernakulam. ${ }^{4}$ Professor, Department of Community Medicine, Sree Narayana Institute of Medical Sciences, Ernakulam, Kerala 5 Assistant Professor in Biostatistics, Department of Community Medicine, Sree Narayana Institute of Medical Sciences, Ernakulam. ${ }^{6}$ Assistant Professor, Department of Community Medicine, Sree Narayana Institute of Medical Sciences, Ernakulam, Kerala. ${ }^{7}$ Assistant Professor, Department of Community Medicine, Sree Narayana Institute of Medical Sciences, Ernakulam, Kerala. ${ }^{8}$ Professor, Department of Community Medicine, Sree Narayana Institute of Medical Sciences, Ernakulam, Kerala.
\end{abstract}

\section{ABSTRACT}

\section{BACKGROUND}

Hypertension is a major public health problem in developing countries across the world, which is a leading cause of cardiovascular disorders worldwide. The prevalence of hypertension and its complications are increasing in developing countries due to economic development, changes in lifestyle and diet and increase in life expectancy. The prevalence will increase even further unless effective preventive measures are implemented. Epidemiological studies are urgently needed to assess the prevalence and risk factors contributing to Hypertension.

The objectives of this study is to estimate the prevalence of hypertension among the outpatients attending a teaching hospital in Central Kerala, to assess the factors associated with hypertension and to determine co-existence of diabetes with hypertension.

\section{MATERIALS AND METHODS}

Cross-sectional study by administrating pre-tested semi-structured questionnaire to all the patients attending Outpatient Department of a Teaching Hospital of Central Kerala after getting their informed consent. Data was analysed to find association between Hypertension and risk factors using chi square test.

\section{RESULTS}

Among the 100 outpatients, 46 males and 54 females, 42 (42\%) were pre-hypertensive and 30 (30\%) were hypertensive. Among those with a sedentary lifestyle, $72.5 \%$ were hypertensive. Among the individuals who exercised regularly, only $4.1 \%$ were hypertensive when compared to those who did not exercise (54.9\%) ( $\mathrm{p}$ value 0.00 ). Of the smokers, 58.8\% were hypertensive ( $\mathrm{p}$ value 0.015 ) and also $73.3 \%$ of those who consumed alcohol. Among those with excessive salt intake, $46.2 \%$ were hypertensive (p value 0.001 ). In subjects who had a family history of hypertension, $48.9 \%$ were hypertensive ( $p$ value 0.001 ). Among the overweight subjects, $58.8 \%$ were hypertensive.

\section{CONCLUSION}

The prevalence of hypertension was 30\% among the outpatients. Appropriate strategies are needed for prevention and control of hypertension to increase awareness about screening programmes and lifestyle modifications.

\section{KEYWORDS}

Prevalence, Hypertension, Outpatients, Risk Factors.

HOW TO CITE THIS ARTICLE: Aravindakshan VN, Vareed SK, Padmanabhan G, et al. Prevalence of hypertension and associated risk factors among patients attending outpatient department of a teaching hospital in Central Kerala. J. Evolution Med. Dent. Sci. 2017;6(7):519-523, DOI: 10.14260/Jemds/2017/110

\section{BACKGROUND}

High blood pressure is a major public health problem in developing countries across the world and is one of the most important modifiable risk factors for cardiovascular diseases.

Financial or Other, Competing Interest: None.

Submission 03-01-2017, Peer Review 15-01-2017,

Acceptance 17-01-2017, Published 23-01-2017.

Corresponding Author:

Dr. Gopalakrishnan Padmanabhan,

Associate Professor,

Department of Community Medicine,

SNIMS, Ernakulam, Kerala.

E-mail: gopalakrishnansnims@gmail.com

DOI: $10.14260 /$ jemds $/ 2017 / 110$
As most of the urban areas have access to health facilities, the hidden mass of hypertension in that community can be detected and treated. However, the situation is reversed in rural areas in India, where a majority of the population have inadequate access to healthcare. Over half of the outpatient consultations are with indigenous and private practitioners, where regular screening for hypertension is not practiced. ${ }^{1}$

Hypertension has been identified as the leading risk factor for mortality and ranked third as the cause of 'disability adjusted life years.' The prevalence of hypertension and its complications are increasing nowadays due to factors like economic development, changes in lifestyle, diet and increase in life expectancy. ${ }^{2}$ 
Hypertension is an iceberg problem which remains silent, being generally asymptomatic during its clinical course. As it is hidden beneath an outwardly asymptomatic appearance, the disease does an immense harm to the body in the form of target organ damage; hence, WHO has named it the silent killer. $^{3}$

Studies have shown that the prevalence of hypertension is more among the urban communities than among rural. With poor detection, treatment and control and challenges of poor awareness and weak capacity for management, prevention programmes still remain the most cost effective option. 4

The World Health Organisation has finalised a set of 9 voluntary global targets that would help in reducing NonCommunicable Diseases (NCDs), particularly hypertension. The voluntary targets are reduction in premature mortality from NCDs by $25 \%$, by 2020 by reducing intake of Alcohol and physical inactivity by $10 \%$ each and intake of salt (sodium) by $30 \%$. This will reduce high blood pressure incidence by $25 \%$. Use of tobacco is targeted to be brought down by $30 \%$ in addition to improving medicines, technology and counselling. Over 140 million people are believed to be suffering from high blood pressure in the country and the number is expected to cross 214 million in 2030. Hypertension is a major risk factor for cardiovascular diseases that killed 2.7 million people in 2004 and is expected to seize the life of over 4 million people by 2030. A WHO estimate in 2008 suggested $33 \%$ men and $32 \%$ women older than 25 yrs. had hypertension in India. As reported by World Health Organisation, hypertension is the $3^{\text {rd }}$ killer disease accounting for 1 in every 8 deaths worldwide. It is directly responsible for $50 \%$ of all stroke deaths and $24 \%$ of all Coronary Heart Disease (CHD) deaths in India. ${ }^{5}$

The aim of this study was to assess the prevalence of hypertension among adult outpatients of a Private Medical College in Central Kerala and to assess the associated factors.
It will provide further information regarding the burden of hypertension and its risk factors to plan further screening and interventions.

\section{MATERIALS AND METHODS}

Approval was obtained from the Institutional Research Committee and Ethics Committee for the study. A crosssectional study using pre-tested semi-structured questionnaire was done. The study setting was a teaching hospital in Central Kerala and the study population was 100 patients (Aged more than 12 years) at outpatient registration desk, who came to attend various outpatient departments and gave consent for examining and participating in the study. Study was conducted during the month of March 2016. After obtaining informed consent from the patients, blood pressure, height and weight were measured and body mass index was computed.

$\mathrm{BP}$ was measured twice at 5 minutes interval in sitting position and averages of these readings were used for classification of Hypertension.

Hypertension was classified as per Joint National Committee (JNC VII) criteria. ${ }^{6}$

\begin{tabular}{|c|c|c|}
\hline Category & $\begin{array}{c}\text { Systolic BP } \\
\text { (mmHg) }\end{array}$ & $\begin{array}{c}\text { Diastolic BP } \\
\text { (mmHg) }\end{array}$ \\
\hline Normal & $<120$ & $<80$ \\
\hline Pre-Hypertension & $120-139$ & $80-89$ \\
\hline Hypertension & $\geq 140$ & $\geq 90$ \\
\hline
\end{tabular}

In our study, we define smokers as those who smoke regularly and alcoholics as those who consume alcohol daily. Those with regular consumption of salted food materials were included in category 'excessive salt intake.'

The collected data were entered in MS-Excel sheet and analysed using SPSS version 17. Frequency and percentage were calculated and Chi square test was used to find association between hypertension and its factors.

\section{RESULTS}

Of the 100 participants who consented for the study, 46 were males and 54 were females. Of them, $42 \%$ were found to be prehypertensive, while $30 \%$ were hypertensive.

\begin{tabular}{|c|c|c|c|c|c|c|}
\hline $\begin{array}{l}\text { Age Group } \\
\text { (Years) }\end{array}$ & $\begin{array}{c}\text { No Hypertension } \\
\text { (Frequency, \%) }\end{array}$ & $\begin{array}{c}\text { Pre-Hypertension } \\
\text { (Frequency, \%) }\end{array}$ & $\begin{array}{l}\text { Hypertension } \\
\text { (Frequency, \%) }\end{array}$ & $\begin{array}{c}\text { Total } \\
\text { (Frequency) }\end{array}$ & \begin{tabular}{|c|}
$\begin{array}{c}\text { Chi Square } \\
\text { value }\end{array}$ \\
\end{tabular} & $P$ value \\
\hline $18-37$ & $6(37.5 \%)$ & $9(56.3 \%)$ & $1(6.2 \%)$ & $16(100 \%)$ & & \\
\hline $38-57$ & $15(26.3 \%)$ & $23(40.4 \%)$ & $19(33.3 \%)$ & $57(100 \%)$ & 5.249 & 0.263 \\
\hline $58-77$ & $7(25.9 \%)$ & $19(37 \%)$ & $10(37.1 \%)$ & 27 (100\%) & & \\
\hline Total & 28 & 51 & 30 & 100 & & \\
\hline \multicolumn{7}{|c|}{ Gender } \\
\hline Female & $18(33.7 \%)$ & $25(46.3 \%)$ & $11(20.0 \%)$ & $54(100 \%)$ & & \\
\hline Male & $10(21.7 \%)$ & $17(37.0 \%)$ & $19(41.3 \%)$ & $46(100 \%)$ & 5.337 & 0.069 \\
\hline Total & 28 & 42 & 30 & 100 & & \\
\hline
\end{tabular}

The prevalence of hypertension was $6.2 \%$ in individuals aged between 18 - 37 yrs., while it was $37.1 \%$ among individuals aged above 57 yrs. Of the 54 female participants 11 (20\%) were hypertensive, while out of 46 males 19 (41.6\%) were hypertensive but it was statistically not significant ( $\mathrm{p}$ value 0.069 ). 


\begin{tabular}{|c|c|c|c|c|c|c|}
\hline Physical Activity & $\begin{array}{c}\text { Normal } \\
\text { (Frequency, \%) }\end{array}$ & $\begin{array}{c}\text { Pre-Hypertension } \\
\text { (Frequency, \%) }\end{array}$ & $\begin{array}{c}\text { Hypertension } \\
\text { (Frequency, \%) }\end{array}$ & Total & $\begin{array}{c}\text { Chi Square } \\
\text { value }\end{array}$ & $P$ value \\
\hline Heavy & $15(44.1 \%)$ & $19(55.9 \%)$ & $0(0.0 \%)$ & $34(100 \%)$ & \multirow{4}{*}{62.73} & \multirow{4}{*}{$<0.001$} \\
\hline Moderate & $13(50.0 \%)$ & $12(46.2 \%)$ & $1(3.8 \%)$ & $26(100 \%)$ & & \\
\hline Sedentary & $0(0.0 \%)$ & $11(27.5 \%)$ & $29(72.5 \%)$ & $40(100 \%)$ & & \\
\hline Total & 28 & 42 & 30 & 100 & & \\
\hline \multicolumn{7}{|c|}{ Exercise } \\
\hline Yes & $18(36.7 \%)$ & $29(59.2 \%)$ & $2(4.1 \%)$ & 49 (100\%) & \multirow{3}{*}{30.887} & \multirow{3}{*}{0.00} \\
\hline No & $10(19.6 \%)$ & $13(25.5 \%)$ & $28(54.9 \%)$ & $51(100 \%)$ & & \\
\hline Total & 28 & 42 & 30 & 100 & & \\
\hline
\end{tabular}

Among 40 subjects who lead a sedentary lifestyle, 29 (72.5\%) were hypertensives. Among the 49 individuals who exercised regularly only $2(4.1 \%)$ were hypertensive, while out of 51 subjects who did not exercise $28(54.9 \%)$ were hypertensive. It was statistically significant $(\mathrm{P}$ value $=0.00)$.

\begin{tabular}{|c|c|c|c|c|c|c|}
\hline Smoking & $\begin{array}{c}\text { Normal } \\
\text { (Frequency, \%) }\end{array}$ & $\begin{array}{c}\text { Pre-Hypertension } \\
\text { (Frequency, \%) }\end{array}$ & $\begin{array}{l}\text { Hypertension } \\
\text { (Frequency, \%) }\end{array}$ & Total & $\begin{array}{c}\text { Chi Square } \\
\text { value }\end{array}$ & $P$ value \\
\hline Yes & $2(11.8 \%)$ & $5(29.4 \%)$ & $10(58.8 \%)$ & 17 (100\%) & \multirow{3}{*}{8.373} & \multirow{3}{*}{0.015} \\
\hline No & $26(31.3 \%)$ & $37(44.6 \%)$ & $20(24.1 \%)$ & $83(100 \%)$ & & \\
\hline Total & 28 & 42 & 30 & 100 & & \\
\hline \multicolumn{7}{|c|}{ Alcohol Intake } \\
\hline Yes & $0(0.0 \%)$ & $4(26.7 \%)$ & $11(73.3 \%)$ & $15(100 \%)$ & \multirow{3}{*}{16.975} & \multirow{3}{*}{$<0.001$} \\
\hline No & $28(32.9 \%)$ & $38(44.7 \%)$ & $19(22.4 \%)$ & $85(100 \%)$ & & \\
\hline Total & 28 & 42 & 30 & 100 & & \\
\hline \multicolumn{7}{|c|}{ Table 3. Association of Hypertension with Smoking and Alcohol Intake } \\
\hline
\end{tabular}

Of 17 smokers, 10 (58.8\%) were hypertensive. But among 83 non-smokers, only 20 (24.1\%) were hypertensive. It was statistically significant (P value 0.015$)$. Out of 15 alcoholics, $11(73.3 \%)$ were hypertensive.

\begin{tabular}{|c|c|c|c|c|c|c|}
\hline $\begin{array}{l}\text { Excessive Salt } \\
\text { Intake }\end{array}$ & $\begin{array}{c}\text { Normal } \\
\text { (Frequency, \%) }\end{array}$ & $\begin{array}{c}\text { Pre-Hypertension } \\
\text { (Frequency, \%) }\end{array}$ & $\begin{array}{c}\text { Hypertension } \\
\text { (Frequency, \%) }\end{array}$ & Total & $\begin{array}{c}\text { Chi Square } \\
\text { value }\end{array}$ & P value \\
\hline Yes & $11(21.2 \%)$ & 17 (33.7\%) & $24(46.2 \%)$ & $52(100 \%)$ & \multirow{3}{*}{13.471} & \multirow{3}{*}{0.001} \\
\hline No & 17 (35.4\%) & 25 (52.1\%) & $6(12.5 \%)$ & $48(100 \%)$ & & \\
\hline Total & 28 & 42 & 30 & 100 & & \\
\hline
\end{tabular}

Among 52 subjects with excessive salt intake, 24 (46.2\%) were hypertensive. It was statistically significant (P value 0.001).

45 subjects had a family history of hypertension and among these $22(48.9 \%)$ were hypertensive and of 55 subjects who did not have a family history only 8 (14.5\%) were hypertensive. It was statistically significant (P value 0.001).

\begin{tabular}{|c|c|c|c|c|c|c|}
\hline Body Mass Index & $\begin{array}{c}\text { Normal } \\
\text { (Frequency, \%) }\end{array}$ & $\begin{array}{c}\text { Pre-Hypertension } \\
\text { (Frequency, \%) }\end{array}$ & $\begin{array}{c}\text { Hypertension } \\
\text { (Frequency, \%) }\end{array}$ & Total & $\begin{array}{c}\text { Chi Square } \\
\text { value }\end{array}$ & P value \\
\hline Underweight & $5(50.0 \%)$ & $5(50.0 \%)$ & $0(0.0 \%)$ & $10(100 \%)$ & \\
Normal & $21(28.8 \%)$ & $32(43.8 \%)$ & $20(27.4 \%)$ & $73(100 \%)$ & 12.07 & 0.017 \\
Overweight/Obese & $2(11.8 \%)$ & $5(29.4 \%)$ & $10(58.8 \%)$ & $17(100 \%)$ & \\
\hline Total & $\mathbf{2 8}$ & $\mathbf{4 2}$ & $\mathbf{3 0}$ & $\mathbf{1 0 0}$ & \\
\hline \multicolumn{7}{|c|}{ Table 5. Association of Hypertension with BMI } \\
\hline
\end{tabular}

Overweight/obesity was more prevalent in females (64.5\%) as compared with males (35.5\%). Among 17 overweight subjects, $10(58.8 \%)$ were hypertensive and in 73 subjects with normal BMI, 20(27.4\%) were hypertensive. Out of 10 underweight subjects, none were hypertensive.

\begin{tabular}{|c|c|c|c|c|c|}
\hline & Diabetic & Non-Diabetic & Total & Chi Square value & P value \\
\hline Normal & $6(21.4 \%)$ & $22(78.6 \%)$ & $28(100 \%)$ & \multirow{4}{*}{5.346} & \multirow{4}{*}{0.069} \\
\hline Pre-Hypertension & $7(16.7 \%)$ & $35(83.3 \%)$ & $42(100 \%)$ & & \\
\hline Hypertension & $12(40.0 \%)$ & $18(60.0 \%)$ & $30(100 \%)$ & & \\
\hline Total & 25 & 75 & 100 & & \\
\hline
\end{tabular}

Out of 30 hypertensives, 12 (40\%) were diabetic and 18 (60\%) were non-diabetic. 


\section{DISCUSSION}

In our study, the prevalence of hypertension was 30\% and pre-hypertension was $42 \%$. The prevalence of hypertension was $24.4 \%$ and pre-hypertension was $29.3 \%$ in a study conducted by Syed Esam Mahmood et al among the adult outpatients of Lucknow. ${ }^{1}$ In a study conducted among the adult tribal population of Kerala state, it was found that $37 \%$ were hypertensives. ${ }^{2}$

In our study, it was found that the prevalence of hypertension was $41.3 \%$ and $20 \%$ among adult men and women respectively. Similarly, a study in urban elderly population in Kerala by Zachariah MG et al reported prevalence of $39 \%$ in males and $29 \%$ in females. ${ }^{7}$ In the study by Syed Esam Mahmood et al, the prevalence of hypertension was higher among females (44.97\%) than among males (42.48\%)

Prevalence of hypertension was more in older age groups: only $6.2 \%$ of individuals who were aged between 18 to 37 years were found to be hypertensive, while $37.1 \%$ of individuals aged above 57 years were hypertensive. However, there was no significant association between age group and prevalence of hypertension ( $p$ value 0.263 ). This was similar to findings of studies conducted among the urban adults of Mumbai and Lucknow and among tribal people of Kerala. ${ }^{1,2}$

The study shows that those who lead a sedentary lifestyle had more prevalence of hypertension (72.5\%). A study conducted in a tribal community of Kerala also reported that sedentary activity was significantly $(\mathrm{p}<0.01)$ associated with hypertension.

The study also reveals smoking (58.8\%, P value -0.015$)$ and alcohol consumption (73.3\%) are associated with hypertension, similar to a study conducted among tribal people of Kerala and Nigerian outpatients. 1,8

In our study, those with a positive family history of hypertension had higher prevalence $(48.9 \%)$ similar to a study conducted on outpatients of Dhaka Medical College (55\%). ${ }^{8}$

It was also observed that prevalence of hypertension was high among those with excessive intake of salt $(46.2 \%, p$ value 0.001). A study conducted in an urban South Indian population showed subjects in the highest quintile of salt intake had significantly higher prevalence of hypertension than did those in the lowest quintile ( 48.4 vs. $16.6 \%$, p < $0.0001) .9$

The study also revealed that the prevalence of hypertension was two-fold among overweight (58.8\%), as compared to normal subjects $(27.4 \%)$ and underweight $(0.05 \%)$, similar to a study conducted among tribal people of Kerala. There is significant association ( $p$ value 0.017 ) between these two variables. A consistent gradient of hypertensive population proportion by BMI group population was observed in a study conducted on Nigerian semi-urban community, rising from $0.0 \%$ in underweight to $10.8 \%$ for normal BMI $62.0 \%$ for overweight. A similar result was also observed in a study conducted on Omani population. ${ }^{10}$

The study showed out of 30 hypertensive 18 (60\%) were diabetic and 12 (40\%) were non-diabetic, similar to a study conducted on outpatients of Dhaka Medical College. ${ }^{11}$

\section{CONCLUSION}

This hospital-based cross-sectional, outpatients department based study was carried out among adults who attended the various clinical departments. The high prevalence of hypertension $(30 \%)$ in the current study confirmed this increasing trend and was similar to the trends which had been reported worldwide.

The proportion of hypertension as well as the mean systolic and diastolic blood pressures was found to increase steadily with an increase in age. The proportion of hypertension was higher among males as compared to that in females.

Association of smoking, alcoholic intake, excessive salt intake with prevalence of hypertension was assessed and found to have a positive association.

As the BMI increases, there is an increase in the prevalence of hypertension. And those with physical inactivity had a higher prevalence of hypertension.

From this study, it was found that in most cases there is a coexistence of diabetes with hypertension.

\section{Recommendations}

Appropriate strategies are needed for prevention and control of hypertension, such as an increasing awareness about regular blood pressure checkup, regular physical exercise and abstinence from alcohol and smoking and reduction of dietary intake of salt.

This study projects the need of an early detection and treatment of hypertension before its complications, which can be facilitated by screening of the people periodically, regularly at the hospital as well as at the community levels and also the prevention of incidence of hypertension by awareness programmes. Epidemiological studies are urgently needed to assess the prevalence and risk factors contributing to hypertension. Intervention measures should be undertaken at the community level; particular emphasis should be placed on prevention by introducing lifestyle modifications and creating awareness about the problem so that early detection and intervention is possible.

\section{Limitations of the Study}

Most of the risk factors were obtained from subjects, as there was no other means of obtaining the information and as such could have been subjected to recall bias. The sample size was also very small. Another major limitation of this study was that the blood pressure pattern estimates were based on the measurements of the blood pressure on a single day and were not repeated again. Also, the subjects for this study were chosen from the outpatients department and thus they may not have been the representatives of the community.

\section{REFERENCES}

[1] Mahmood SE, Prakash D, Srivastava JP, et al. Prevalence of hypertension amongst adult patients attending outpatient department of urban health training centre, department of community medicine, era's Lucknow medical college and hospital, Lucknow. J Clin Diagn Res 2013;7(4):652-6.

[2] Meshram II, Arlappa N, Balkrishna N, et al. Prevalence of hypertension, its correlates and awareness among adult tribal population of Kerala state, India. J Postgrad Med 2012;58(4):255-61. 
[3] Yuvaraj BY, Gowda NMR, Umakantha AG. Prevalence, awareness, treatment and control of hypertension in rural areas of Davanagere. Indian J Community Med 2010;35(1):138-41.

[4] Suleiman IA, Amogu EO, Ganiyu KA. Prevalence and control of hypertension in a Niger Delta semi urban community, Nigeria. Pharm Pract (Granada) 2013;11(1):24-9.

[5] Hypertension major contributor to avoidable deaths in India: WHO. The Hindu NEW DELHI, March 16, 2013, www.thehindu.com/hypertension-major-contributorto avoidable-deaths in India (accessed on $13^{\text {th }}$ March 2016).

[6] Park K. Park's textbook of preventive and social medicine. 22nd edn. Chapter 6, Jabalpur, India. M/s Banarsidas Bhanot Publishers 2013:p 344.

[7] Gudina EK, Michael Y, Assegid S. Prevalence of hypertension and its risk factors in southwest Ethiopia; a hospital-based cross-sectional survey, US national library of medicine national institutes of health. Integr Blood Press Control 2013;6:111-7.
[8] Awobusuyi J, Adebola A, Ajose F. Prevalence and sociodemographic profile of hypertensive patients in a nigerian general out-patients department. Internet Journal of Third World Medicine 2012;10(1).

[9] Radhika G, Sathya RM, Sudha V, et al. Dietary salt intake and hypertension in an urban south Indian population-[CURES - 53]. J Assoc Physicians India 2007;55:405-11.

[10] Al-Maqbali AA, Temple-Smith M, Ferler J, et al. Prevalence and determinants of pre-hypertension among omani adults attending non-communicable disease screening program in primary care setting in sohar city. Oman Med J 2013;28(5):316-23.

[11] Kabir A, Barman TK, Yousuf NA, et al. Prevalence of hypertension among the patients who attend medicine outdoor of Dhaka medical college hospital. Journal of Medicine 2008;8(2):49-52. 